\title{
Preferential trading arrangements and industrial location ${ }^{*}$
}

\author{
Diego Puga \\ Centre for Economic Performance, \\ London School of Economics \\ Anthony J. Venables \\ London School of Economics \\ and Centre for Economic Policy Research \\ CENTRE for ECONOMIC PERFORMANCE \\ Discussion Paper No. 267, October 1995
}

\begin{abstract}
This paper considers the locational effects of geographically discriminatory trade policy. A preferential move towards a free trade area pulls industry into the integrating countries. Input-output links between imperfectly competitive firms amplify this effect and, when trade barriers fall below some critical level, may lead to agglomeration with some member countries gaining industry at the expense of others. A hub-andspoke arrangement favours location in the hub, with better reciprocal access to spoke nations than these have to each other. Further liberalisation induces agglomeration in the hub and may trigger disparities between the spokes.
\end{abstract}

* This paper was produced as part of the Programme on International Economic Performance at the UK Economic and Social Research Council funded Centre for Economic Performance, London School of Economics. Financial support from the Banco de España (Puga) and the British Taiwan Cultural Institute (Venables) is gratefully acknowledged.

KEY WORDS: integration, free trade area, hub-and-spoke, agglomeration.

JEL CLASSIFICATION: F12, F15, R12.

Correspondence address:

Diego Puga

Centre for Economic Performance

London School of Economics

Houghton Street

London WC2A 2AE, UK

d.puga@lse.ac.uk

http: //dpuga.lse.ac.uk 


\section{Introduction}

In recent years, Canada, the United States (US), and Mexico have liberalised trade between themselves significantly more than they have with the rest of the world. The member states of the European Union (EU) made earlier moves in the same direction and have taken integration further with the Single European Act. Trade within the North American Free Trade Agreement (NAFTA) already accounts for a third of the total trade of Canada, the United States, and Mexico. Similarly, over two-thirds of EU trade takes place within the Union. And regional trade in these two areas alone represents more than one half of world trade.

The NAFTA and the EU are the largest of more than seventy preferential trading arrangements (PTAs) notified to meet article XXIV of the General Agreement on Tariffs and Trade. Yet internal disputes sometimes overshadow the achievements of regional integration in these and other geographical areas. One of the main concerns in the countries engaged in a preferential trade liberalisation is that it may trigger a relocation of industry, perhaps of catastrophic proportions. ${ }^{[1]}$

Our objectives in this paper are to study the effects of PTAs on the location of industry and the consequent effects on welfare. We look at two different forms of PTA, free trade areas and hub-and-spoke arrangements, and analyse two issues. ${ }^{[2]}$ First, how does industry relocate between countries inside and outside the PTA? Is industry drawn into the PTA, and if so is it the case that gains for the integrating region come partly at the expense of those left outside (perhaps because a more integrated region can attract industry from other countries, as firms find it advantageous to sell to member countries from inside the PTA)? Second, how do firms relocate between member countries of the PTA? We show that formation of a PTA does not necessarily cause convergence of the production structures and welfare levels of member nations. It may trigger agglomeration of activity, causing divergence of structure and income levels across member states.

\footnotetext{
1 Recall the row between the French and British governments over the decision by Hoover to concentrate its vacuum cleaner production in Glasgow and to eliminate 600 jobs at its plant in Dijon, or Ross Perot's prediction of a 'giant sucking sound' of firms and jobs leaving the United States to Mexico following the NAFTA (The Economist, 6 February 1993 and 18 September 1993 respectively).

2 The analysis is conducted in quite general form and other multi-country trade policy reform experiments can be analysed using equations given in the appendix.
} 
Our approach to these issues is to focus on the location of firms operating in an imperfectly competitive environment. What essential ingredients do we need to use in order to develop a formal model that addresses these concerns about industrial relocation? The first important element is the conjunction of increasing returns to scale (which induce firms to concentrate their production) and positive trade barriers (which make their choice of location important). Krugman's (1980) model of trade with Dixit and Stiglitz (1977)-type monopolistic competition is the basis for formalising this.

Second, as geographers and development economists have long noted, firms tend to cluster together drawn by the availability of a large base of suppliers, which in turn is due to the concentration of demand. To capture this circularity we consider, as Krugman and Venables (1995) do, an imperfectly competitive industrial sector that produces goods that are demanded for final consumption and also used as intermediate inputs. That creates forward (cost) and backward (demand) linkages between firms, and a tendency for agglomeration.

The third essential ingredient of the model is a trading system with more than two potential locations for firms, in order to make geographically discriminatory trade policy possible. We develop the general framework for any number $M$ of countries, and then particularise it when expositional clarity so requires.

To put all these features together in a tractable model we rely on some familiar tricks, namely symmetry between firms and consumers, which enables us to talk in terms of representative agents, and particular functional forms. Despite the loss of generality, we believe that the results are quite suggestive and illustrative of the tendencies, if not of the magnitudes, that one would learn if able to solve a more realistic model.

The remainder of the paper is structured as follows. The next section sets up the formal model, which is based on Krugman and Venables (1995). Section 3 illustrates how differences in production structures across countries can arise, even without differences in technology, endowments, or trade policy. Section 4 develops the comparative statics analysis of a PTA, in the absence of agglomeration. It shows that a preferential move towards a free trade area pulls industry into the integrating countries. Similarly, a hub-and-spoke arrangement favours location in the hub, which 
has better reciprocal access to spoke nations than these have to each other. Section 5 looks at the stability of the equilibrium as trade policy changes, and shows how agglomeration may be triggered during a PTA. In the free trade area case, integration beyond some critical level can open up differences in production in the integrating countries. However, if these are associated with wage divergence, further integration may close the gap. In the hub-and-spoke case, liberalisation shifts industry into the hub region, and when a critical level of integration is reached the relocation process may accelerate suddenly. If different employment levels induce divergence in wages, further integration may also trigger disparities between the spoke countries. A concluding section includes a discussion of empirical evidence on the effects analysed in the paper.

\section{A formal model}

Consider a trading system with $M$ countries. Country $i$ is endowed with $L_{i}$ units of labour, the only primary factor of production. There are two production sectors. The commodity sector is perfectly competitive. It produces under constant returns to scale, using one unit of labour per unit of output, a homogeneous commodity that is costlessly tradeable and will serve as numéraire.

The industrial sector has imperfectly competitive firms, producing differentiated goods under increasing returns to scale. Following Dixit and Stiglitz (1977), production of a quantity $x_{i}(k)$ of any variety $k$ in any country $i$ requires the same fixed $(\alpha)$ and variable $\left(\beta x_{i}(k)\right)$ quantities of the production input. As in Venables (1996), that production input is a Cobb-Douglas composite of labour and an aggregate of the differentiated industrial goods. Following Ethier (1982), all varieties enter symmetrically into this constant elasticity of substitution (CES) intermediate aggregate.

The cost function of a firm producing variety $k$ in country $i$ is

$$
C_{i}(k)=q_{i}^{\mu} w_{i}^{(1-\mu)}\left(\alpha+\beta x_{i}(k)\right),
$$

where $w_{i}$ is the wage, and $q_{i}$ is the price index of the aggregate, defined by 


$$
q_{i} \equiv\left[\sum_{j=1}^{M} \int_{h \in N_{j}}\left(p_{j, i}(h) \tau_{j, i}\right)^{(1-\sigma)} \mathrm{d} h\right]^{1 /(1-\sigma)} .
$$

The price index in each country depends on the local prices of individual varieties, which in turn are a function of the free on board (FOB) prices and trade barriers. The elasticity of substitution between varieties, $\sigma>1$, is assumed to be the same in all countries. $N_{j}$ is the set of varieties produced in location $j$, and $p_{j, i}(h)$ is the FOB price of variety $h$ shipped from country $j$ to country $i$. Trade barriers for the industrial goods take Samuelson's 'iceberg' form: $\tau_{j, i}$ units have to be shipped from country $j$ so that one unit arrives in $i$. Given this cost function, proportions $\mu$ and $(1-\mu)$ of costs are spent on intermediates and labour respectively.

The representative consumer in each nation has Cobb-Douglas preferences over the commodity and a CES aggregate of the industrial goods. For convenience, we assume it is the same CES aggregate that enters firms' technology. Therefore, each firm is both an upstream supplier of intermediate inputs to other firms and a downstream producer for final consumer demand. The indirect utility of the representative consumer in country $i$ is

$$
V_{i}=q_{i}^{-\gamma} 1^{-(1-\gamma)} m_{i}
$$

where $m_{i}$ is income, $\gamma$ is the share of industrial goods, and $(1-\gamma)$ is the share of the numéraire.

The division of consumers' and producers' expenditure on industrial goods between individual varieties can be found by using Roy's identity on the indirect utility function and Shephard's lemma on the cost function. The demand faced in market $i$ by a firm producing variety $k$ in country $j$, denoted $x_{j, i}(k)$, is

$$
x_{j, i}(k)=p_{j, i}(k)^{-\sigma}\left(\frac{\tau_{j, i}}{q_{i}}\right)^{(1-\sigma)}\left[\gamma m_{i}+\mu \int_{h \in N_{i}} C_{i}(h) \mathrm{d} h\right],
$$

where the term in square brackets is the value of country $i$ consumers' plus intermediate expenditures on industrial goods, amounting to fractions $\gamma$ of income and $\mu$ of industrial costs. 
Firms sell in each country, and perceive a constant own price demand elasticity of $\sigma$ in every market. All firms producing in any particular location have the same profit maximising FOB price, which is a constant relative mark-up over marginal cost,

$$
p_{i}=\frac{\sigma \beta}{\sigma-1} q_{i}^{\mu} w_{i}^{(1-\mu)} .
$$

If firms enter and exit in response to positive and negative profits, at equilibrium industrial sector profits will be exhausted in every country. There is a unique level of output that gives firms zero profits,

$$
x=\frac{\alpha(\sigma-1)}{\beta} .
$$

All firms in a particular location are symmetric, and we shall define the mass of varieties produced in location $i$ by $n_{i} \equiv \# N_{i}$ (and generally refer to it as the number of firms in location $i$ ), and the output of each by $x_{i}$. At equilibrium,

$$
\left(x_{i}-x\right) n_{i}=0, x_{i} \leq x, \quad n_{i} \geq 0 .
$$

Turning to the labour market, the commodity sector demands labour perfectly elastically at wage 1 , so market clearing wages are higher than unity only in those countries specialised in the production of industrial goods. Since the value of industrial labour demand is $(1-\mu) n_{i} C_{\mathrm{i}}$, this gives equilibrium wage

$$
w_{i}=\max \left\{1, \frac{(1-\mu) n_{i} C_{i}}{L_{i}}\right\}=\max \left\{1, q_{i}\left[\frac{(1-\mu) n_{i} \alpha \sigma}{L_{i}}\right]^{1 / \mu}\right\},
$$

where the second equation uses both the definition of costs (1) and the zero profit condition, (6) and (7). At equilibrium the only source of consumer income is the wage, so

$$
m_{i}=w_{i} L_{i}
$$


This completes the description of equilibrium. There are four locational forces which together determine the equilibrium distribution of firms across locations. Product and labour market competition tend to make firms located in markets with relatively many firms less profitable, thereby encouraging the geographical dispersion of industry. Product market competition is stronger in locations where more varieties are produced locally in the sense that the price index of industrial goods is lower - expression (2) - so that, for a given price and level of expenditure, local demand for each industrial good is smaller -expression (4). Stronger labour market competition in industrialised regions appears in expression (8): if a country becomes specialised in industrial production local wages will be higher, this increasing firms' costs.

Pushing in the opposite direction there are what Hirschman (1958) calls 'forward and backward linkages'. In this model, forward linkages come from the assumption that firms use the output of other firms as an input $(\mu>0)$. A larger number of locally produced varieties, other things being equal, implies a lower price index of industrial goods, and therefore lower total and marginal costs of production -expression (1). Backward linkages arise as an increase in the number of local firms raises local expenditure on intermediates - expression (4). Forward and backward linkages tend to increase the profitability of locations with a larger number of firms. When they are strong enough they can overturn product market and labour market competition thereby making dispersed outcomes unstable and triggering industrial agglomeration.

In order to proceed analytically, it is useful to rewrite the equilibrium conditions in vector form. Let $n, \boldsymbol{q}$, and $\boldsymbol{L}$ denote (M-column) vectors with representative elements $n_{i} q_{i}$ and $L_{i}$, respectively. Superscript ${ }^{\mathrm{T}}$ denotes transpose; and superscript $\wedge$ denotes a diagonal matrix with the $i$ th element of the corresponding vector in position $(i, i)$, and zeros off the diagonal. I is the identity matrix, and $\mathrm{l}$ denotes the (column) vector of ones. Let us also introduce matrix $\theta$, with representative element

$$
\theta_{i, j} \equiv \tau_{i, j}^{(1-\sigma)} .
$$

Here and in the next two sections we focus on equilibria where some quantity of the numéraire is produced in every nation, so wages are constant and equal to unity. 
Let us choose units for $\alpha=1 / \sigma$ and $\beta=(\sigma-1) / \sigma$. Using (1), (4), (5), (6) and (9) in (7) gives the zero profit condition as

$$
0=\theta\left[\gamma \hat{L} q^{(\sigma-1)}+\mu \hat{q}^{(\mu+\sigma-1)} n\right]-q^{\sigma \mu} \equiv \pi(n, q, \theta),
$$

Expression (11) gives $M$ equations in the numbers of firms (vector $n$ ) and the price indices of industrial goods (vector $q$ ) in the $M$ countries, given parameters $\gamma, \mu, \sigma$, and the matrix of trade barriers $\theta$. The definition of the $M$ price indices of expression (2), once we substitute in the pricing equation (5), gives the remaining $M$ equations necessary to solve the system:

$$
0=\theta^{\mathrm{T}} \hat{\boldsymbol{q}}^{\mu(1-\sigma)} n-\boldsymbol{q}^{(1-\sigma)} \equiv Q(n, q, \theta)
$$

where the functions $\pi$ and $Q$ are convenient ways to carry the analysis.

Equilibrium values of the number of firms and the price index of industrial goods in each of the $M$ countries are a simultaneous solution to (11) and (12). Let us focus on symmetric changes in trading arrangements, characterised by a matrix $d \theta\left(=d \theta^{\mathrm{T}}\right)$ of changes in the trade policy matrix $\theta$. Totally differentiating (11) and (12) and rearranging gives the following comparative statics:

$$
\begin{gathered}
\mathrm{d} n=\left[\pi_{n}-\pi_{q} Q_{q}^{-1} Q_{n}\right]^{-1}\left[\mathrm{~d} \theta \pi_{\theta}-\pi_{q} Q_{q}^{-1} \mathrm{~d} \theta Q_{\theta}\right], \\
\mathrm{d} q=Q_{q}^{-1} Q_{n}\left[\pi_{n}-\pi_{q} Q_{q}^{-1} Q_{n}\right]^{-1}\left[\mathrm{~d} \theta \pi_{\theta}-\pi_{n} Q_{n}^{-1} \mathrm{~d} \theta Q_{\theta}\right],
\end{gathered}
$$

where $\pi_{n}, \pi_{q}, Q_{n}, Q_{q}$ are matrices of partial derivatives, and $\pi_{\theta}, Q_{\theta}$ are vectors of partial derivatives. Explicit forms for all these are given in the appendix.

In the following sections we shall use (13) and (14) to establish the location and price effects of a trade policy change $d \theta$. These effects depend on the matrix $\left[\pi_{n}-\pi_{q} Q_{q}^{-1} Q_{n}\right]$, which is related to the stability of the system in the following way. Under myopic entry/exit adjustment, the location dynamics can be written as

$$
\dot{n}=F[\pi(n, q, \theta)],
$$


where $\dot{\boldsymbol{n}}$ denotes the vector of changes (with respect to time) of the number of firms in the $M$ countries, and function $F$ is such that $F^{\prime}>0$ and $F(0)=0$. Linearising this system of differential equations around equilibrium, and using (11) and (12), gives:

$$
\left(1 / F^{\prime}\right) \dot{n}=\left[\pi_{n}-\pi_{q} Q_{q}^{-1} Q_{n}\right] \mathrm{d} n
$$

The local stability of the system depends on the eigenvalues of its Jacobian matrix, $\left[\pi_{n}-\pi_{q} Q_{q}^{-1} Q_{n}\right]$, evaluated at equilibrium. This matrix is symmetric, so if all its eigenvalues are negative the equilibrium is a stable node, and if all its eigenvalues are positive then the equilibrium is an unstable node. If some eigenvalues are positive and some are negative then the corresponding equilibrium is a saddle point —and therefore unstable, as there are no 'jump' variables.

We now proceed in three steps. First (section 3), we look at the stability of a symmetric equilibrium where all countries are the same size, face the same trade barriers, and have the same number of firms. We do this by investigating the eigenvalues of the Jacobian matrix of the system defined by (15). Second (section 4), we look at the comparative statics of different trade policy experiments $d \theta$, using expressions (13) and (14). Finally (section 5), we pull together the comparative statics and stability analysis to investigate the possibility that PTAs may lead to agglomeration. In principle, this implies looking at the eigenvalues of $\left[\pi_{n}-\pi_{q} Q_{q}^{-1} Q_{n}\right]$ for non-symmetric cases. In practice, we only do so for particular parameter values.

\section{Global integration}

Before analysing PTAs, let us look at the benchmark case where all firms, regardless of their location, have equal access to any foreign market. That is, $\tau_{i, j}=\tau$ for all $i \neq j$. By letting $\tau$ fall we can capture a process of global integration. ${ }^{[3]}$

Suppose that initially trade barriers between all countries are very high. Each nation is then essentially self-sufficient, with domestically oriented production in both sectors. If there are no differences in labour endowments, a symmetric equilibrium

\footnotetext{
3 This trade policy experiment is a multi-country generalisation of Krugman and Venables (1995).
} 
exists where all countries have identical values for all endogenous variables, and therefore the same number of firms.

Now think of a global reduction in trade barriers. The symmetric equilibrium still exists, but now involves some intraindustry trade. At high global trade barriers, the need to be close to final consumer demand dominates linkages. However, at low enough global trade barriers, forward and backward linkages give higher profits to firms located in countries with a larger industry, and when trade barriers fall below a critical level the symmetric equilibrium ceases to be stable. To show this we need to look at the Jacobian matrix of the system defined by (16), $\left[\pi_{n}-\pi_{q} Q_{q}^{-1} Q_{n}\right]$, in the neighbourhood of the symmetric equilibrium. It is shown in the appendix that the Jacobian matrix passes from being negative definite to indefinite as trade barriers fall below the critical value

$$
\tau^{*}=\left(1+\frac{M \mu(2 \sigma-1)}{(1-\mu)[\sigma(1-\mu)-1]}\right)^{1 /(\sigma-1)} .
$$

Therefore, for values of trade barriers higher than this the symmetric equilibrium is a stable node. As trade barriers fall below $\tau^{*}$, the symmetric equilibrium becomes saddle point unstable. The critical value is higher, and therefore agglomeration takes place earlier during global integration, the larger are the input-output links and scale economies. ${ }^{[4]}$ Table 1 illustrates this dependence when $M=3$, for values of $\mu$ and $\sigma$ specified in rows and columns respectively.

When global trade barriers fall below the critical level of expression (17), and the symmetric equilibrium becomes unstable, there are multiple stable asymmetric equilibria where some countries have a larger share of industry than others. ${ }^{[5]}$ However, since all nations are ex ante identical, which countries gain and which lose industry with respect to the symmetric equilibrium is indeterminate.

4 If economies of scale and input-output links between firms are very large (to the point that $\sigma(1-\mu)<1)$, the symmetric equilibrium may be unstable for any level of $\tau$.

5 Asymmetric equilibria exist below a value of trade barriers higher than the critical value of expression (17), so for some intermediate range of trade barriers there are multiple stable equilibria. 
TABLE 1

Critical values of trade barriers $(\tau)$

below which the symmetric equilibrium is saddle point unstable $(M=3)$.

\begin{tabular}{l|cccc} 
& \multicolumn{4}{c}{ Elasticity of substitution $(\sigma)$} \\
\cline { 2 - 5 } Share of & 4 & 5 & 6 \\
\cline { 2 - 5 } intermediates in & 0.2 & 1.50 & 1.34 & 1.26 \\
costs & 0.3 & 1.82 & 1.54 & 1.40 \\
$(\mu)$ & 0.4 & 2.22 & 1.78 & 1.57
\end{tabular}

The precise characterisation of the asymmetric equilibria varies with the number of countries and the share of industry in consumer expenditure. The case where there are only two nations is relatively simple, and has been described in some detail by Krugman and Venables (1995). If world demand for industrial goods is small enough to be supplied by a single country (to be precise, if $\gamma \leq 1 / 2$ ), at the asymmetric equilibria both sectors are active in one nation, while the other one specialises in the production of the commodity. If the share of intermediates in consumer expenditure is larger $(\gamma \geq 1 / 2)$, one country fully specialises in the production of industrial goods; whether the other one produces some industrial goods depends on the values of parameters (see Krugman and Venables, 1995, for the relevant conditions on parameters).

The three country case is a straightforward generalisation of the two country case. If world demand for industrial goods is small (if $\gamma \leq 1 / 3$ ), at the asymmetric equilibria both sectors are active in one nation, while the other two specialise in the production of the commodity. If the share of intermediates in consumer expenditure is larger $(1 / 3<\gamma \leq 2 / 3)$, one of the three countries fully specialises in the production of industrial goods; whether either or both of the other two produce some industrial goods depends on the values of parameters. Finally, if $\gamma>2 / 3$, industry absorbs the entire labour force in two of the countries, and the third one either specialises in the production of the commodity or has a smaller number of firms. 
In cases where agglomeration causes some countries to fully specialise in industrial production, wages in those countries rise relative to wages elsewhere. The size of the sustainable wage gap depends on trade barriers, and falls as these become very small.

\section{Preferential trading arrangements without agglomeration}

We want to establish the effects of changes in trade policy, as represented by the matrix $\theta$. The natural benchmark for this analysis is the symmetric equilibrium, however we know from the analysis of the preceding section that this is not always stable. We therefore start the analysis assuming that trade barriers are higher than the critical value of expression (17) so there is no agglomeration of industry, moving on to look at agglomeration in the following section.

Starting from a stable symmetric equilibrium, countries implement a trade policy change $\mathrm{d} \theta$. The comparative statics are then given by (13) and (14). These expressions look formidable, but, using the symmetric case forms from the appendix and expression (3), they simplify considerably to give locational changes

$$
\mathrm{d} n=\theta^{-1}\left[(1-\sigma)(1-\mu)(\mathrm{I}-\mu \theta)\left[\mathrm{I} \mu(2 \sigma-1) t-\theta\left(\mu^{2} \sigma+\sigma-1\right)\right]^{-1}-\mathrm{I} / t\right] \mathrm{d} \theta \mathrm{\imath} .
$$

The associated real income changes are

$$
\mathrm{d} V=-\gamma\left[\mathrm{I} \mu(2 \sigma-1)-\theta\left(\mu^{2} \sigma+\sigma-1\right) / t\right]^{-1}[(1-\mu) / t] \mathrm{d} \theta \imath .
$$

In these equations $t$ is defined as the row (or column) sum of elements of $\theta$. Notice the simple form in which direct effects enter the system: $d \theta t$ is the sum of row changes in the trade policy matrix $\theta$. In expressions (18) and (19), $d \theta \imath$ postmultiplies matrices which - in the symmetric case - have all diagonal elements the same and all off-diagonal elements the same (explicit forms of these elements are given in the appendix).

Defining the appropriate trade policy change matrix, $d \theta$, it is now routine to derive the location and welfare changes of any PTA that departs from a stable symmetric equilibrium. We focus on two types of PTAs, free trade areas and hub-and-spoke arrangements. 


\section{The formation of a free trade area}

A free trade area involves a liberalisation of trade flows between its members (if they also implement a common external trade policy, the free trade area becomes a customs union). To analyse its consequences both for the integrating countries and for the rest of the world, let the number of countries then be $M=3$, an assumption that we shall maintain for the remainder of the paper. A preferential move towards a free trade area, with countries 1 and 2 as members and reciprocal trade barriers between each of them and 3 unchanged, is characterised by the trade liberalisation matrix

$$
\mathrm{d} \theta=\left[\begin{array}{lll}
0 & \mathrm{~d} \theta_{1,2} & 0 \\
\mathrm{~d} \theta_{1,2} & 0 & 0 \\
0 & 0 & 0
\end{array}\right],
$$

where $\mathrm{d} \theta_{1,2}=(1-\sigma) \tau^{-\sigma} \mathrm{d} \tau_{1,2}=(1-\sigma) \tau^{-\sigma} \mathrm{d} \tau_{2,1}>0$.

Expression (18), using the explicit forms for matrix elements of the appendix, gives the locational changes with respect to the symmetric equilibrium as

$$
\begin{gathered}
\frac{\mathrm{d} n_{1}}{\mathrm{~d} \theta_{1,2}}=\frac{\mathrm{d} n_{2}}{\mathrm{~d} \theta_{1,2}}=\frac{\mathrm{B}+\mu}{\left(1+2 \tau^{(1-\sigma)}\right)[\sigma(1-\mu)-1]}>0, \\
\frac{\mathrm{d} n_{3}}{\mathrm{~d} \theta_{1,2}}=\frac{-2 \mathrm{~B}}{\left(1+2 \tau^{(1-\sigma)}\right)[\sigma(1-\mu)-1]}<0,
\end{gathered}
$$

where $\mathrm{B}$ is a function of parameters - explicitly defined in the appendix - that is positive if and only if the initial symmetric equilibrium is stable - as we have assumed to be the case.

These equations capture what Baldwin and Venables (1995) call 'production shifting'. Intuitively, firms producing in the liberalising countries can export their product within the free trade area subject to lower trade barriers than firms located outside. This allows firms inside the free trade area to expand production and make positive profits, while firms located outside it contract production and make negative profits. Free entry and exit restores profits back to zero, as country 3 firms relocate into 1 and 2. Production shifting into the free trade area is larger the stronger are 
input output links - although the effect persists even if $\mu=0$. Gains from production shifting are reinforced by an increase in the total size of industry in the free trade area, which arises because the lower barriers on intermediates traded within the free trade area reduce production costs for firms in 1 and 2 and increase their profitability -this being captured by the term $\mu$ in the numerator of expression (21). ${ }^{[6]}$

With respect to welfare effects, it can similarly be shown, using (19) and the explicit forms for matrix elements of the appendix, that

$$
\frac{\mathrm{d} V_{1}}{\mathrm{~d} \theta_{1,2}}=\frac{\mathrm{d} V_{2}}{\mathrm{~d} \theta_{1,2}}>0, \quad \frac{\mathrm{d} V_{3}}{\mathrm{~d} \theta_{1,2}}<0 .
$$

Note that since trade barriers are assumed to be real, they yield no rent so there are no revenue effects. Welfare rises in each of the integrating countries for three reasons. First, the reduction in barriers gives a direct cost saving on internal trade. Second, production is shifted into the free trade area, so fewer varieties used by local firms (in consumption and as intermediates) are subject to trade barriers. And third, if $\mu>0$, the total number of varieties available increases, this bringing gains from product differentiation. Welfare falls in country 3 because fewer varieties are now produced locally, this result holding even if $\mu>0$.

\section{Hub-and-spoke arrangements}

The relations between the countries forming a PTA, as well as between intersecting free trade areas have become increasingly complex. For instance, the Association Agreements between the EU and several Central and East European countries (CEECs) have bilaterally liberalised trade between the EU and each of these CEECs. They have not, however, addressed trade barriers between the CEECs, nor have they included all CEECs. The term 'hub-and-spoke' has been coined for these type of arrangements that give one region (the hub) better access to other regions (the spokes) than these have to each other (see Baldwin, 1994, and Kowalczyk and Wonnacott, 1992, for a discussion of hub-and-spoke arrangements in Europe and America respectively).

\footnotetext{
${ }^{6}$ For large policy changes, the increase in the total number of firms in the free trade area has a positive second order effect on the number of firms in 3, as it tends to lower their costs. However, this effect is eclipsed by the negative first order effect of production shifting into the free trade area.
} 
A hub-and-spoke arrangement that bilaterally reduces trade barriers between country 1 and countries 2 and 3, without affecting trade barriers between 2 and 3, is defined by the trade liberalisation matrix

$$
\mathrm{d} \theta=\left[\begin{array}{lll}
0 & \mathrm{~d} \theta_{1, i \neq 1} & \mathrm{~d} \theta_{1, i \neq 1} \\
\mathrm{~d} \theta_{1, i \neq 1} & 0 & 0 \\
\mathrm{~d} \theta_{1, i \neq 1} & 0 & 0
\end{array}\right],
$$

where $\mathrm{d} \theta_{1, i \neq 1}=(1-\sigma) \tau^{-\sigma} \mathrm{d} \tau_{1, i}=(1-\sigma) \tau^{-\sigma} \mathrm{d} \tau_{i, 1}>0, i=2,3$.

Similarly to the free trade area case, the location effects of this hub-and-spoke arrangement can be derived from expression (18) as

$$
\begin{gathered}
\frac{\mathrm{d} n_{1}}{\mathrm{~d} \theta_{1, i \neq 1}}=\frac{2(\mathrm{~B}+\mu)}{\left(1+2 \tau^{(1-\sigma)}\right)[\sigma(1-\mu)-1]}>0, \\
\frac{\mathrm{d} n_{2}}{\mathrm{~d} \theta_{1, i \neq 1}}=\frac{\mathrm{d} n_{3}}{\mathrm{~d} \theta_{1, i \neq 1}}=\frac{-\mathrm{B}+\mu}{\left(1+2 \tau^{(1-\sigma)}\right)[\sigma(1-\mu)-1]}<\frac{\mathrm{d} n_{1}}{\mathrm{~d} \theta_{1, i \neq 1}} .
\end{gathered}
$$

To interpret these results, imagine first that there are no input-output links between firms. Then $\mu=0$, and expressions (25) and (26) imply that $\mathrm{d} \boldsymbol{n}_{2} / \mathrm{d} \theta_{1,2}=\mathrm{d} \boldsymbol{n}_{3} / \mathrm{d} \theta_{1,2}=-1 / 2 \mathrm{~d} \boldsymbol{n}_{1} / \mathrm{d} \theta_{1,2}<0$. Intuitively, firms located in country 1 (the hub) can sell to consumers in 2 and 3 (the spokes) at a lower trade cost than firms exporting from one spoke to the other. A hub-and-spoke arrangement thus gives, other things being equal, hub firms relatively larger demand, and shifts industry out of the spokes. This is what Krugman (1993) calls the 'hub effect'.

Introducing input-output links has two consequences. First, firms in 2 and 3 are penalised by a smaller demand not only by consumers but, with a positive $\mu$, also by firms using industrial goods as intermediates in the other spoke. This reinforces the shift of industrial production into 1. Second, firms in the spokes now face lower trade barriers when importing intermediate inputs from the hub, and vice versa. This, other things being equal, reduces production costs, raises firm profitability, and increases the size of industry in the hub and also in the spokes - as captured respectively by 
the term $2 \mu$ in the numerator of expression (25) and the term $\mu$ in the numerator of (26).

Welfare effects can be also calculated from (19), which gives

$$
\frac{\mathrm{d} V_{1}}{\mathrm{~d} \theta_{1, i \neq 1}}>0, \quad \frac{\mathrm{d} V_{2}}{\mathrm{~d} \theta_{1, i \neq 1}}=\frac{\mathrm{d} V_{3}}{\mathrm{~d} \theta_{1, i \neq 1}}<\frac{\mathrm{d} V_{1}}{\mathrm{~d} \theta_{1, i \neq 1}} .
$$

Overall, a hub-and-spoke arrangement unambiguously increases the number of firms and welfare in the hub. In spoke nations the number of firms and welfare certainly increases by less than in the hub and may fall, the latter being more likely the lower are initial trade barriers.

\section{Regional asymmetries and agglomeration}

\section{Regional disparities during the formation of a free trade area}

Section 4 looked at the effects of trade policy when parameters are such that the initial symmetric equilibrium is stable and agglomeration does not occur. We now look at cases where the PTA triggers agglomeration, and address three questions. First, when does agglomeration take place? Second, what are the characteristics of the ensuing equilibrium? And finally, what are the welfare consequences for each country?

Suppose integration starts at a stable symmetric equilibrium, where the Jacobian matrix of the system, $\left[\pi_{n}-\pi_{q} Q_{q}^{-1} Q_{n}\right]$, is locally negative definite. Agglomeration takes place as $\tau_{1,2}\left(=\tau_{2,1}\right)$ falls below the critical value at which matrix $\left[\pi_{n}-\pi_{q} Q_{q}^{-1} Q_{n}\right]$, valued at the relevant equilibrium (with $n$ and $\boldsymbol{q}$ solutions to $Q(n, \boldsymbol{q}, \theta)=0$ and $\pi(n, q, \theta)=0)$, becomes indefinite. At that point the equilibrium where both integrating countries have the same number of firms switches from being a stable node to an unstable saddle point. Whereas in section 3 we were able to derive a closed form solution for the critical value of trade costs at which the symmetric equilibrium becomes stable, now - because of the asymmetry created by the PTAwe are forced to use numerical methods. We thus produce table 2 (analogous to table 1 -and with which it shares one critical point: $\tau_{i, j}=1.57$, for all $i \neq j$ ). Given linkages and external trade barriers in each row and column respectively, and $\sigma=6$, 


\section{TABLE 2}

Critical values of internal trade barriers $\left(\tau_{1,2}=\tau_{2,1}\right)$ below which the equilibrium where both countries forming a free trade area have the same number of firms is saddle point unstable

Share of intermediates in costs

$(\mu)$

\begin{tabular}{c|ccc}
\multicolumn{3}{c}{} & \multicolumn{3}{c}{ External trade cost } \\
& 1.57 & 1.85 & 2 \\
\hline 0.2 & 1.22 & 1.21 & 1.20 \\
0.3 & 1.37 & 1.34 & 1.33 \\
0.4 & 1.57 & 1.51 & 1.49
\end{tabular}

bifurcation occurs as internal trade barriers fall below the specified critical level. A higher $\mu$, which represents stronger linkages, makes bifurcation take place earlier during the formation of a free trade area. So do lower external trade barriers, which make industry more footloose.

What happens to the share of industry in each country once internal trade barriers fall below the critical value? At the ensuing equilibrium one of the countries in the free trade area (we shall assume 1) gains firms, the other one (in this case 2) loses firms, while the effect on the size of industry in country 3 is ambiguous. Let us look at a representative example. Figure $1 a$ (drawn for parameters $\gamma=0.6, \mu=0.4$, and $\sigma=6$ ) plots the evolution of the share of industry located in each country, $s_{i}$, as trade barriers between 1 and 2 fall. Integration starts at a symmetric equilibrium where for all $i \neq j \tau_{i, j}=1.85$. The first stages of integration during the formation of a free trade area lead to the same increase in the size of industry in countries 1 and 2, and to a fall in the size of industry in 3, as we saw in section 4 . As internal trade barriers fall below the critical level $\tau_{1,2}=\tau_{2,1}=1.51$ (table 2 ), the number of firms in country 1 increases while the share of industry in 2 falls below that of $3 .^{[7]}$

7 Note that even before this critical level is reached, there is some range of internal trade barriers $\left(1.51<\tau_{1,2}=\tau_{2,1}<1.56\right)$ for which linkages are not strong enough to destabilise the symmetric equilibrium. Yet they are sufficient to ensure that if country 1 already had all its labour force employed in industry, that would be a stable equilibrium as well. These two stable equilibria are represented in the figure. 


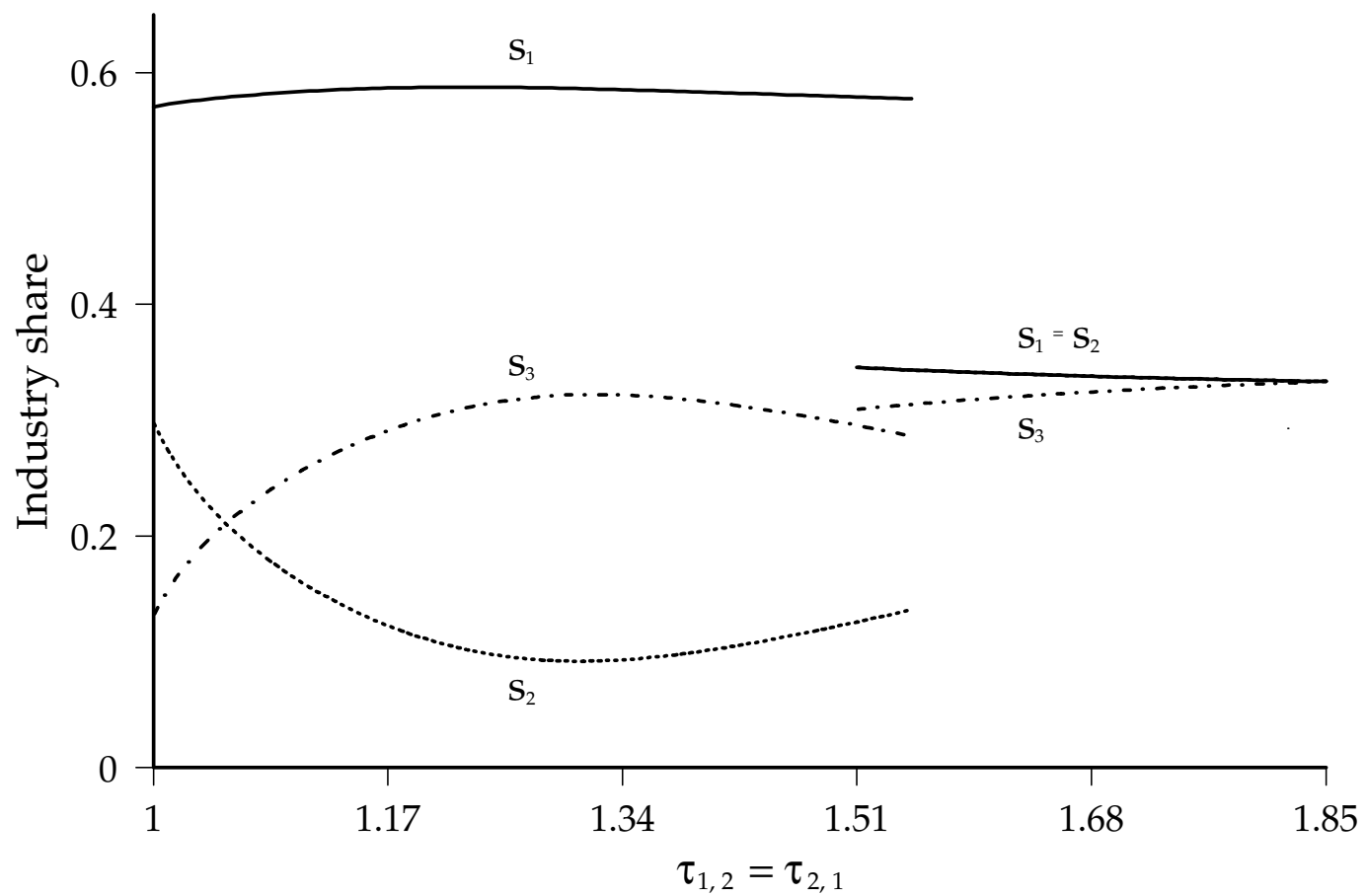

FIGURE $1 a$

The formation of a free trade area: Share of industry in each country

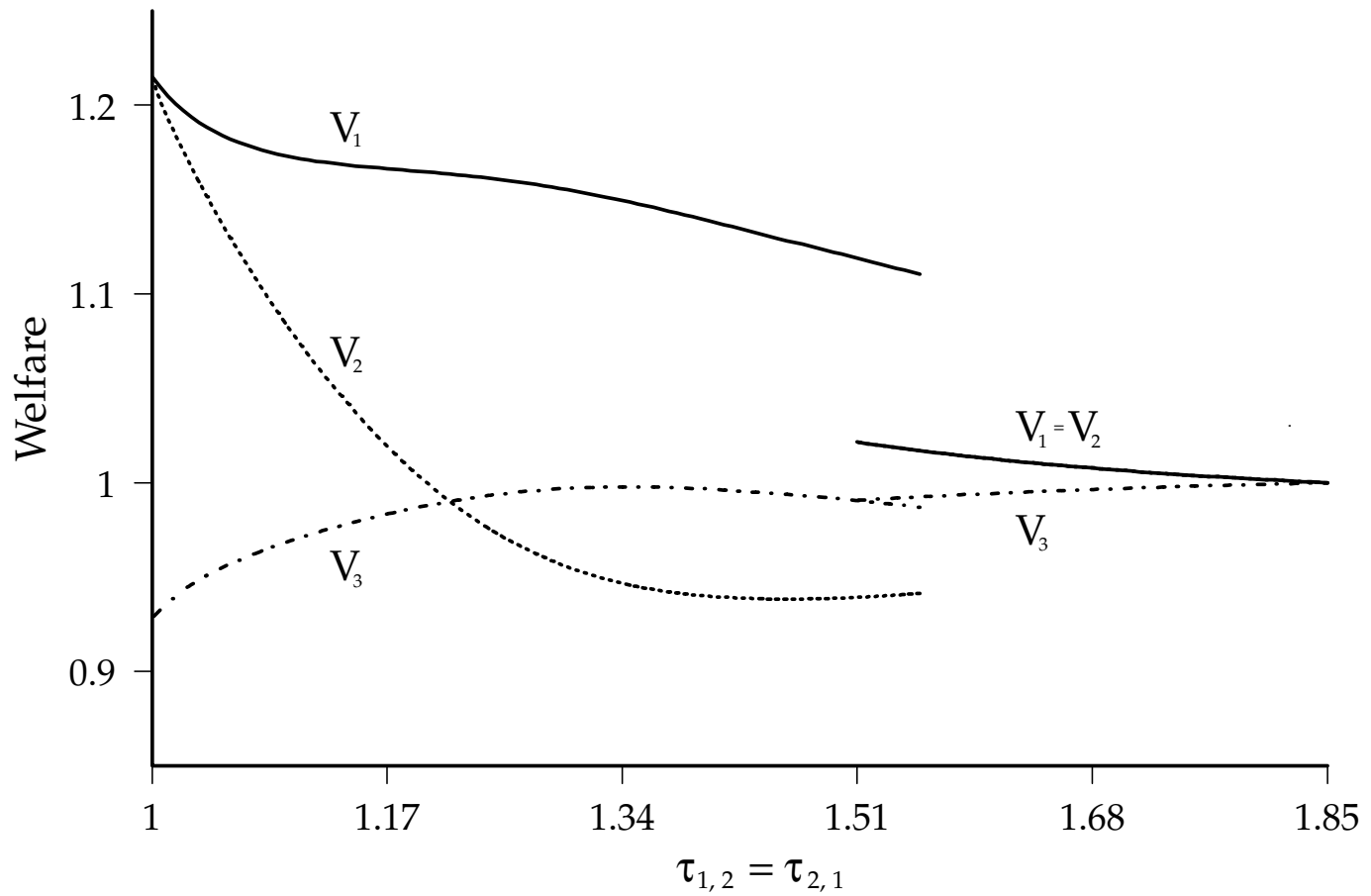

FIGURE $1 b$

The formation of a free trade area: Welfare effects 
Further integration beyond the critical level makes markets with larger expenditure more attractive locations. That has the effect of increasing industrial employment in 3 at the expense of 2. In 1, with all its labour already employed by industry, the larger labour demand translates into higher wages instead. However, as internal trade barriers continue to fall, location becomes increasingly sensitive to differences in production costs. At low enough internal barriers $\left(\tau_{1,2}=\tau_{2,1}=1.3\right)$, country 2 starts reattracting firms because of its increasingly good access to country 1 and its low labour costs, despite having a smaller local base of suppliers. Country 3 simultaneously begins to lose firms. As $\tau_{1,2}\left(=\tau_{2,1}\right)$ approaches unity, the share of industry in country 2 gets closer to that of 1 , reducing differences in wages between the two countries.

Figure $1 b$ plots the evolution of welfare corresponding to figure $1 a$. Although welfare effects are not directly caused by the evolution in country shares of industry they are closely related with it. Countries with more industry have higher labour demand and have to import fewer varieties subject to trade barriers, both effects supporting the real income differences in figure $1 b$. Until agglomeration takes place welfare changes are driven by members of the free trade area incurring lower trade barriers on their usage of manufacturing, and changes in the total number of varieties available. The formation of a free trade area between countries 1 and 2 initially increases their welfare levels as industry shifts into them, while welfare decreases in 3. The additional feature giving rise to the large welfare differentials in figure $1 b$ is the fact that when internal trade barriers fall below the critical level $\tau_{1,2}=\tau_{2,1}=1.51$, country 1 specialises in manufacturing and the wage in this country rises above wages elsewhere. Because a larger share of goods are produced locally instead of being imported, the price index drops in 1, raising welfare further. In 2 welfare falls instead following firm exit - in the figure, below the welfare level of country 3 . However, as internal trade barriers continue to fall so there is relocation of production from country 1 to country 2 , and the wage gap between 1 and 2 narrows, with internal factor price equalisation achieved in the limit. ${ }^{[8]}$

8 Countries are identical in technology and endowments, so at perfectly free trade the location of production within the free trade area is indeterminate. 


\section{TABLE 3}

Critical values of trade barriers between the hub and the spokes

$$
\left(\tau_{1,2}=\tau_{2,1}=\tau_{1,3}=\tau_{3,1}\right) \text { at which bifurcation occurs }
$$

Trade cost between spoke countries

\begin{tabular}{ll|ccc} 
& \multicolumn{3}{c}{$\left(\tau_{2,3}=\tau_{3,2}\right)$} \\
& & 1.57 & 1.85 & 2 \\
\cline { 2 - 5 } Share of & 0.2 & 1.34 & 1.36 & 1.37 \\
intermediates in & 0.3 & 1.44 & 1.47 & 1.48 \\
costs & 0.4 & 1.57 & 1.61 & 1.62 \\
$(\mu)$ & & &
\end{tabular}

How general is the picture drawn in this example? Under the assumptions of the model, the agglomeration of industry in one of the integrating countries is a general outcome (with the value of internal trade barriers at which it occurs depending on parameter values). However, the large wage gap after agglomeration in the figures is due to the high share of industrial goods in consumer expenditure $(\gamma=0.6)$. For low values of $\gamma$ when industry agglomerates in 1 this country may keep some production in the commodity sector, in which case there is neither a temporarily higher wage in country 1 nor subsequent catch up by country $2 .{ }^{[9]}$

\section{Hub-and-spoke arrangements, agglomeration and divergence}

Having discussed in detail the logic of sudden change in the free trade area case, let us now close the argument by sketching the corresponding analysis for hub-andspoke arrangements. A bilateral trade liberalisation between country 1 and countries 2 and 3, leaving unchanged barriers between the latter two, starts shifting industrial

9 That differences in wages only arise when a country fully specialises in industrial production is a special feature of the model, a consequence of the L-shaped labour demand schedule in the commodity sector. If some curvature is introduced in the labour demand schedule by the commodity sector, wage differentials arise even without full specialisation, this making agglomeration more difficult and lowering the sustainable wage gap faster as countries integrate 


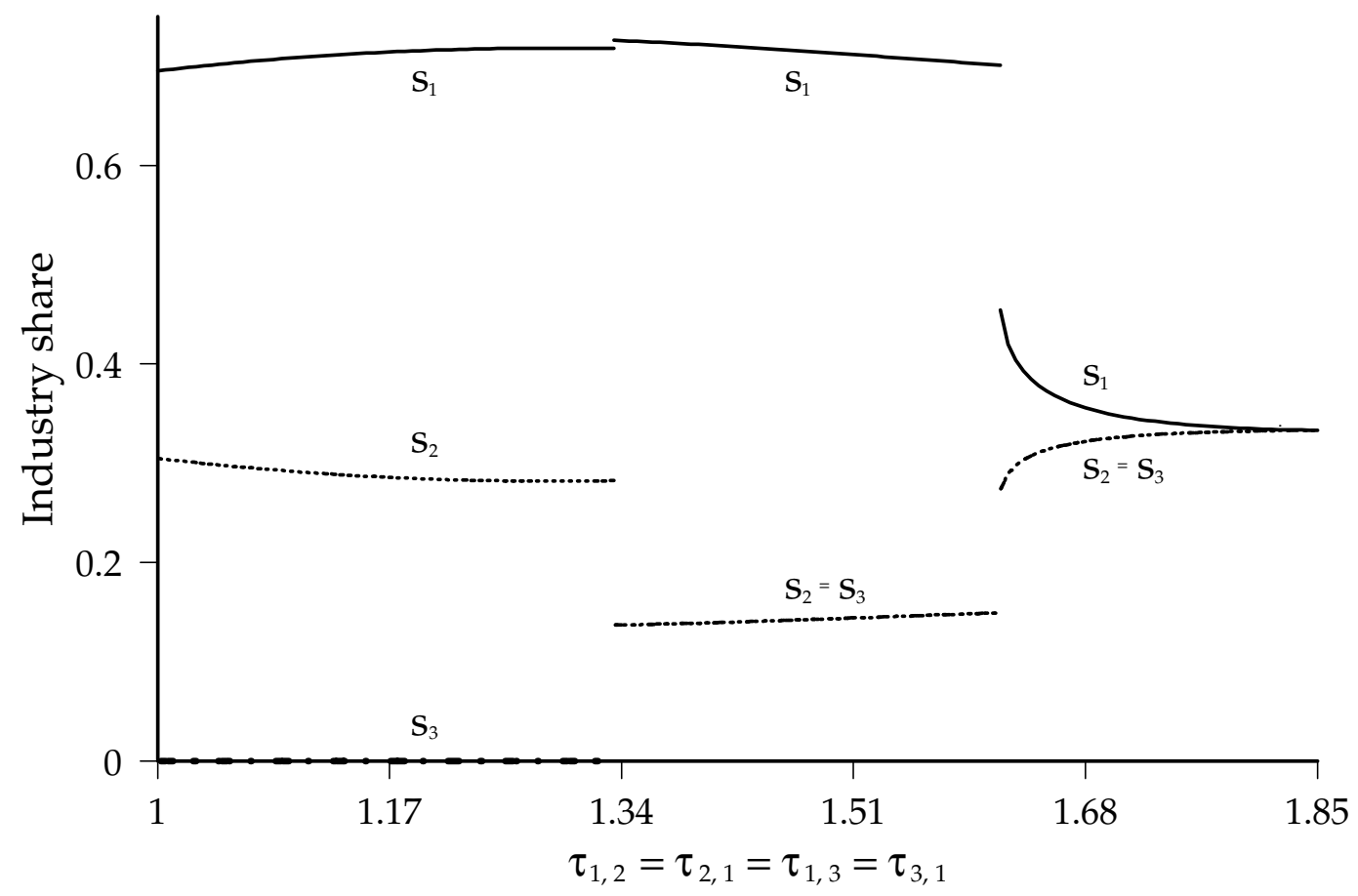

FIGURE $2 a$

A hub-and-spoke arrangement: Share of industry in each country

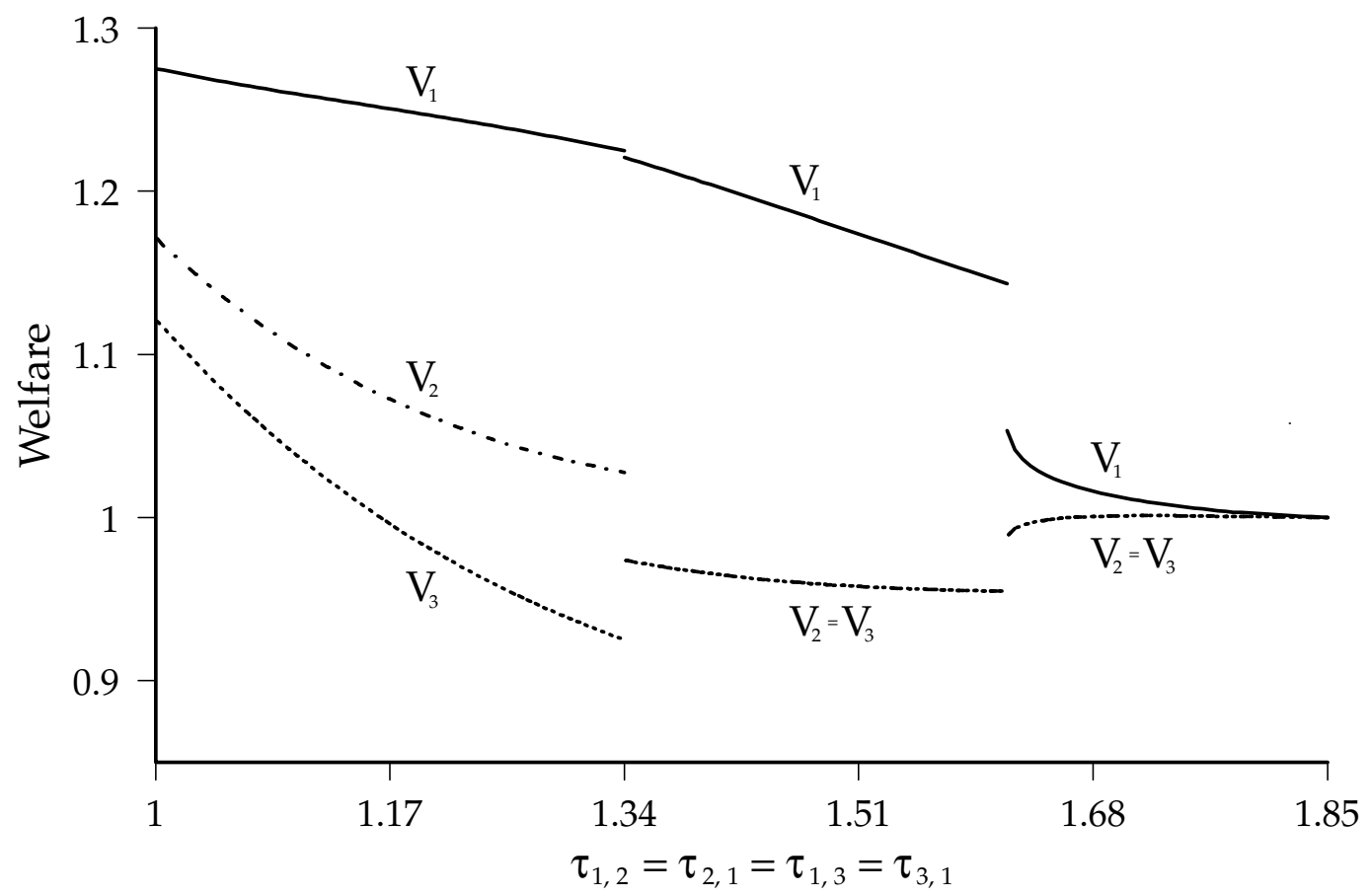

FIGURE $2 b$

A hub-and-spoke arrangement: Welfare effects 
production into 1 gradually. However, when a critical level of integration is reached, agglomeration in the hub takes place suddenly.

Table 3 gives the level of bilateral trade barriers at which the matrix $\left[\pi_{n}-\pi_{q} Q_{q}^{-1} Q_{n}\right]$ ceases to be locally negative definite and bifurcation occurs. Linkages are given in each row, and trade barriers between the spokes in each column, while $\sigma=6$ throughout. Higher trade barriers between the spokes and stronger linkages bring sudden change earlier during a gradual hub-and-spoke trade liberalisation.

Figure $2 a$ plots the evolution of industrial location (for parameters $\gamma=0.5, \mu=0.4$, $\sigma=6$, and $\left.\tau_{2,3}=\tau_{3,2}=1.85\right)$. When bilateral trade barriers fall below the critical level $\tau_{1,2}=\tau_{2,1}=\tau_{1,3}=\tau_{3,1}=1.61$ (table 3 ), country 1 becomes fully specialised in industrial production. Hub wages then rise above those paid in the spokes. As hub-and-spoke trade liberalisation goes further, location becomes increasingly sensitive to cost differences. ${ }^{[10]}$

At low enough bilateral trade barriers $\left(\tau_{1,2}=\tau_{2,1}=\tau_{1,3}=\tau_{3,1}=1.34\right)$, the equilibrium where 2 and 3 have the same number of firms becomes unstable and a second bifurcation occurs. If one of the spokes (country 2 in figure $2 a$ ) has a larger share of industry than the other, its firms can buy intermediates at a lower cost and reduce prices. That lowers demand for firms producing in other markets. In country 1 the market-clearing wage consistent with zero profits falls, leaving industrial employment unaffected. In 3 any wage cut leads industrial workers to seek employment in the commodity sector, and firms exit as industry expands in 2 . Figure $2 b$ plots the evolution of welfare corresponding to figure $2 a$. Hub-and-spoke integration, if pushed far enough, can raise welfare in all countries involved. Yet it is a way of opening up trade that not only favours the hub, but can also end up triggering divergence between the spokes.

10 If agglomeration in the hub does not lead to wage divergence, as hub-and-spoke integration goes on beyond this critical level, industry keeps growing in country 1 and shrinking in 2 and 3 . 


\section{Summary and conclusions}

The analysis of the paper draws a stylised picture of how industrial location may change in response to preferential trading arrangements (PTAs). A move towards a free trade area lets imperfectly competitive firms in the integrating countries sell their output to (and import intermediates from) other member countries at lower trade barriers, as compared to firms outside the free trade area. That raises the profitability of firms located in the liberalising nations, and shifts industry into them.

Input-output links create a tendency for firms to cluster together in markets with a larger base of suppliers, which in turn is due to the concentration of demand. During the initial stages of integration, high internal trade barriers provide an incentive to supply national markets locally. All member states of the free trade area then benefit identically from integration, while industry size and welfare fall outside the liberalising regions.

As integration proceeds, the incentive for self-sufficiency weakens. And when internal trade barriers fall below some critical level, the circular process of agglomeration created by input-output links endogenously produces a core-periphery structure, as some regions in the free trade area gain industry at the expense of others. As a result, while the formation of a free trade area benefits the integrating region as a whole, during the intermediate stages of integration some member countries may have lower welfare levels than countries outside the arrangement. Further integration initially leads to wider divergence. But if changing industrial employment has an impact on wages, then there is a point beyond which less industrialised countries inside the free trade area are able to reattract a share of industry. They do so on the basis of good access to the internal market and low labour costs, despite lacking a large local base of suppliers. Therefore, a firm and credible commitment to full integration may convince peripheral regions to put up with harder times during the intermediate stages of trade liberalisation. So will transfers from the core regions, which redistribute the aggregate gains that the free trade area achieves during the whole integration process.

Turning to hub-and-spoke arrangements, firms located in the spoke countries are penalised by a lower demand by both consumers and firms in the other spokes, as 
compared to that enjoyed by hub firms. Spoke firms also have larger costs, as they face higher barriers than hub firms when importing intermediates from the other spokes. A hub-and-spoke arrangement thus shifts industrial production into the hub. It has been argued (see Baldwin, 1994) that, although the Association Agreements are better than no trade liberalisation at all, they will marginalise Central and East European countries (CEECS) by turning them into the spokes of the European Union hub. Similarly, Kowalczyk and Wonnacott (1992) have argued that Canada will benefit more from a free trade area with the United States and Mexico than from a hub-andspoke system centred on the US, although a hub-and-spoke liberalisation would have been better for Canada than giving up its free trade area with the US. Our results formally corroborate this argument. They also establish that cumulative causation in the location decision of firms may make production shifting more rapid and dramatic than expected. Integration beyond some critical level may accelerate agglomeration in the hub suddenly. Moreover, if higher industrial employment in the hub induces divergence in wages, further integration may also trigger disparities between the spoke countries. Differences between the CEECs were one of the reasons argued against a multilateral rather than bilateral approach to trade liberalisation in the first place. If hub-and-spoke arrangements widen regional divergences, they may become increasingly difficult to replace.

How much evidence is there to support that PTAs cause such changes in the production structure of nations? Hanson (1994), using data on Mexico, finds support for the hypothesis that agglomeration is associated with increasing returns. He also shows (Hanson, forthcoming) that integration with the Us has had strong effects on industry location in Mexico. Industry has shifted towards states with good access to the US market. At the same time, employment growth has been higher in regions that have larger agglomerations of industries with buyer/supplier relationships. With respect to Europe, Brülhart and Torstensson (1996) show that scale intensive industries in the EU tend to be highly concentrated in space, and located close to the geographical core of the EU. Using regional EU data, they also find some support for the U-shaped relationship between the degree of regional integration and spatial agglomeration that our model predicts: activities with larger scale economies were 
more concentrated in regions close to the geographical core of the EU during the early stages of European integration, while concentration in the core has fallen in the 1980s.

While these examples provide some support for our findings, more work is clearly needed in this area. We hope that the clear predictions arising from this framework will help encourage much needed empirical testing on the location effects of preferential trading arrangements.

\section{Appendix}

Explicit forms for vectors and matrices of partial derivatives. At the symmetric equilibrium we choose units for $\boldsymbol{L}$ such that $q=1$, and hence $\boldsymbol{n}=\mathrm{l} / \mathrm{t}$, where

$$
t \equiv 1+(M-1) \tau^{(1-\sigma)} .
$$

The partial derivatives of the text are given in the following set of equations, in each of which the first expression gives the general form, and the second evaluates this at the symmetric equilibrium.

$$
\begin{aligned}
& Q_{n}=\theta^{\mathrm{T}} \hat{q}^{\mu(1-\sigma)}=\theta \\
& Q_{q}=\theta^{\mathrm{T}} \hat{\boldsymbol{n}} \mu(1-\sigma) \hat{\boldsymbol{q}}^{[\mu(1-\sigma)-1]}-(1-\sigma) \hat{\boldsymbol{q}}^{-\sigma}=(1-\sigma)[\theta(\mu / t)-\mathrm{I}], \\
& \pi_{n}=\theta \mu \hat{q}^{(\mu+\sigma-1)}=\theta \mu, \\
& \pi_{q}=\theta \gamma \hat{L}(\sigma-1) \hat{q}^{(\sigma-2)}+\theta \mu(\mu+\sigma-1) \hat{q}^{(\mu+\sigma-2)} \hat{n}-\sigma \mu \hat{q}^{(\sigma \mu-1)} \\
& =\theta\left(\mu^{2} \sigma+\sigma-1\right) / t-I \sigma \mu, \\
& Q_{\theta}=\hat{q}^{\mu(1-\sigma)} n=\imath / t, \\
& \pi_{\theta}=\left[\gamma \hat{L} q^{(\sigma-1)}+\mu \hat{q}^{(\mu+\sigma-1)} n\right]=\imath / t
\end{aligned}
$$


Derivation of the critical value in the symmetric case. The Jacobian matrix of the system, $\left[\pi_{n}-\pi_{q} Q_{q}^{-1} Q_{n}\right]$, valued at the symmetric equilibrium, has identical diagonal elements

$$
\frac{-\tau^{(1-\sigma)}\left\{\left(\mu^{2} \sigma+\sigma-1\right)\left(1-\tau^{(1-\sigma)}\right)-\left[1+(M-1) \tau^{(1-\sigma)}\right][\sigma(1-\mu)-1]-\left(1-\tau^{(1-\sigma)}\right) A\right\}}{(\sigma-1)\left\{(1-\mu)+[(M-1)+\mu] \tau^{(1-\sigma)}\right\}},
$$

where

$$
\mathrm{A} \equiv\left(1-\tau^{(1-\sigma)}\right)(1-\mu)[\sigma(1-\mu)-1]-\tau^{(1-\sigma)} M \mu(2 \sigma-1)
$$

and identical off-diagonal elements

$$
\frac{-\tau^{(1-\sigma)}\left\{\left(\mu^{2} \sigma+\sigma-1\right)\left(1-\tau^{(1-\sigma)}\right)-\left[1+(M-1) \tau^{(1-\sigma)}\right][\sigma(1-\mu)-1]\right\}}{(\sigma-1)\left\{(1-\mu)+[(M-1)+\mu] \tau^{(1-\sigma)}\right\}} .
$$

Provided that $\sigma(1-\mu)>1$, the Jacobian matrix is negative definite if and only if $A>0$, which is the case if and only if $\tau$ is larger than the critical value of equation (17) in the text.

Location and welfare changes. The matrix

$$
\theta^{-1}\left[(1-\sigma)(1-\mu)(\mathrm{I}-\mu \theta)\left[\mathrm{I} \mu(2 \sigma-1) t-\theta\left(\mu^{2} \sigma+\sigma-1\right)\right]^{-1}-\mathrm{I} / t\right],
$$

which, when postmultiplied by $\mathrm{d} \theta \mathrm{r}$, as in expression (18), gives the location effects of a trade policy change $\mathrm{d} \theta$ in the neighbourhood of the symmetric equilibrium, has identical diagonal elements

$$
\frac{(M-1) \mathrm{B}+\mu}{\left[1+(M-1) \tau^{(1-\sigma)}\right][\sigma(1-\mu)-1]},
$$

and identical off-diagonal elements

$$
\frac{-\mathrm{B}}{\left[1+(M-1) \tau^{(1-\sigma)}\right][\sigma(1-\mu)-1]},
$$

where 


$$
\mathrm{B} \equiv \frac{\tau^{(1-\sigma)}(\sigma-1)\left(\mu^{2} \sigma+\sigma-1\right)\left[1+(M-1) \tau^{(1-\sigma)}-\mu\left(1-\tau^{(1-\sigma)}\right)\right]+\mu \sigma \tau^{(1-\sigma)} \mathrm{A}}{\left(1-\tau^{(1-\sigma)}\right) \mathrm{A}} .
$$

Matrix

$$
-\gamma\left[\operatorname{I} \mu(2 \sigma-1)-\theta\left(\mu^{2} \sigma+\sigma-1\right) / t\right]^{-1}[(1-\mu) / t]
$$

which, when postmultiplied by $\mathrm{d} \theta \mathrm{r}$, as in expression (19), gives the welfare effects of a trade policy change $\mathrm{d} \theta$ in the neighbourhood of the symmetric equilibrium, has identical diagonal elements

$$
\gamma \frac{(M-1) \tau^{(1-\sigma)}\left(\mu^{2} \sigma+\sigma-1\right)+\mathrm{A}}{\left[1+(M-1) \tau^{(1-\sigma)}\right][\sigma(1-\mu)-1] \mathrm{A}}
$$

and identical off-diagonal elements

$$
-\gamma \frac{\left(\mu^{2} \sigma+\sigma-1\right) \tau^{(1-\sigma)}}{\left[1+(M-1) \tau^{(1-\sigma)}\right][\sigma(1-\mu)-1] A} .
$$

If the symmetric equilibrium is stable, $\mathrm{A}>0$, and $\mathrm{B}>0$, and both the matrix of expression (A 11) and the matrix of expression (A 15) have positive diagonal elements and negative off-diagonal elements, with the former larger in absolute value than the latter.

\section{References}

Baldwin, Richard E. 1994. Towards an Integrated Europe. London: Centre for Economic Policy Research.

Baldwin, Richard E. and Anthony J. Venables. 1995. 'Regional economic integration.' In Gene M. Grossman and Kenneth Rogoff (eds.). Handbook of International Economics, 3, Amsterdam: North-Holland: 1597-1644.

Dixit, Avinash K. and Joseph E. Stiglitz. 1977. 'Monopolistic competition and optimum product diversity.' American Economic Review, 67: 297-308.

Brülhart, Marius and Johan Torstensson. 1996. 'Regional integration, scale economies and industry location.' Discussion Paper No. 1.435, Centre for Economic Policy Research. 
Ethier, Wilfred J. 1982. 'National and international returns to scale in the modern theory of international trade.' American Economic Review, 72: 389-405.

Hanson, Gordon H. 1994. 'Regional adjustment to trade liberalisation.' Working Paper No. 4713, National Bureau of Economic Research.

Hanson, Gordon H. Forthcoming. 'Increasing returns, trade, and the regional structure of wages.' Economic Journal.

Hirschman, Albert O. 1958. The Strategy of Economic Development. New Haven, Connecticut: Yale University Press.

Kowalczyk, Carsten and Ronald J. Wonnacott. 1992. 'Hubs and spokes, and free trade in the Americas.' Working Paper No. 4198, National Bureau of Economic Research.

Krugman, Paul R. 1980 'Scale economies, product differentiation, and the pattern of trade.' American Economic Review, 70: 950-959.

Krugman, Paul R. 1993 'The hub effect: or, threeness in interregional trade.' In Wilfred J. Ethier, Elhanan Helpman, and J. Peter Neary (eds.). Theory, Policy and Dynamics in International Trade. Cambridge: Cambridge University Press: 29-37.

Krugman, Paul R. and Anthony J. Venables. 1995. 'Globalization and the inequality of nations.' Quarterly Journal of Economics, 110: 857-880.

Venables, Anthony J. 1996. 'Equilibrium locations of vertically linked industries.' International Economic Review, 37: 341-359. 